\title{
Conservadorismo, posicionamento político e preconceito contra casais adotivos homossexuais
}

José Victor de Oliveira Santos. Universidade Federal do Piauí Ludgleydson Fernandes de Araújo. Universidade Federal do Piauí Elder Cerqueira-Santos. Universidade Federal de Sergipe Fauston Negreiros. Universidade Federal do Piauí

\section{Resumo}

A presente pesquisa teve como objetivo geral analisar a influência do conservadorismo, posicionamento político e preconceito sexual direcionado à avaliação de casais que buscam adoção. Participaram da coleta de dados 731 pessoas, autodeclaradas 39,5\% homens $(n=289)$ e $60,5 \%$ mulheres $(n=442)$ com a idade variando de 18 a 69 anos, tendo como média 27,6 anos $(D P=8,93)$. Os instrumentos foram compostos por escalas direcionadas ao posicionamento político, escore de conservadorismo, adoção entre casais e dados sociodemográficos. Os resultados mostram que o conservadorismo é significativo associado à avaliação do casal lésbico e do casal gay (em menor intensidade), não sendo representativo para o casal heterossexual. A orientação política de esquerda apresentou mais favorabilidade a casais gays do que os outros modelos, os de direita foi significativo para gays e lésbicas. Outro fato, é que quanto mais amigos homossexuais, maior a aceitação aos casais de gays e lésbicas. Segure-se que os dados sirvam como escopo em futuras investigações.

Palavras-chave: adoção homoparental; conservadorismo; preconceito; posicionamento político.

\section{Abstract}

Conservatism, political positioning, and prejudice against gay adoptive couples. The present research had as general objective to analyze the influence of conservatism, political positioning and sexual prejudice directed to the evaluation of couples seeking adoption. A total of 731 individuals, self-reported 39.5\% men $(n=289)$ and 60.5\% women $(n=442)$, ranging in age from 18 to 69 years, mean 27.6 years $(S D=8.93)$. The instruments were composed of scales directed to the political positioning, conservatism score, adoption among couples and sociodemographic data. The results show that the conservatism is significant associated to the evaluation of the lesbian couple and the gay couple (to a lesser extent), being not representative for the heterosexual couple. The result documented that conservatism is significantly associated with the assessment of the lesbian couple and the gay couple (to a lesser extent), and is not significant for the heterosexual couple. The leftist political orientation presented more favoritism to gay couples than the other models, the rightwing was significant for gays and lesbians. Another fact is that the more homosexual friends, the greater the favorability of gay and lesbian couples. The data serve as scope in future investigations.

Keywords: homoparental adoption; conservatism; preconception; political positioning.

\section{Resumen}

Conservadorismo, posicionamiento político y preconcepto contra las parejas homosexuales. La presente investigación tuvo como objetivo general analizar la influencia del conservadurismo, posicionamiento político y prejuicio sexual dirigido a la evaluación de parejas que buscan adopción. En la colecta de datos 731 personas, autodeclaradas 39,5\% hombres $(n=289)$ y $60,5 \%$ mujeres ( $n=442)$ con la edad varía de 18 a 69 años, teniendo como promedio 27,6 años $(D P=8,93)$. Los instrumentos fueron compuestos por escalas dirigidas al posicionamiento político, escaso de conservadurismo, adopción entre parejas y datos sociodemográficos. Los resultados muestran que el conservadurismo es significativo asociado a la evaluación del matrimonio lésbico y de la pareja gay (en menor intensidad), no siendo representativo para la pareja heterosexual. La orientación política de izquierda mostró más favorables a las parejas gays que los otros modelos, los de derecha fue significativo para gays y lesbianas. Otro hecho, es que cuanto más amigos homosexuales, mayor es la favorable a las parejas de gays y lesbianas. Se sostendrá que los datos sirvan como ámbito en futuras investigaciones.

Palabras clave: adopción homoparental; conservadorismo; preconcepto; posicionamiento político. 
Frente às diversas constituições familiares que ganham visibilidade na contemporaneidade, as famílias homoparentais, monoparentais e recompostas se integram ao modelo nuclear, que ainda hoje é posta como padrão, como visto em estudos prévios (Cerqueira-Santos \& Santana, 2015). Sabe-se que são todas construções sociais que se moldam com o avanço da sociedade e neste ponto que cada vez mais as chamadas "novas construções familiares" buscam prover parentalidade (Dias \& Reinheimer, 2013). A adoção de crianças e adolescentes por casais formados por pessoas do mesmo sexo é um tema que tem tido muita repercussão na atualidade, que está associado ao crescimento de famílias homoparentais, cujo Instituto Brasileiro de Geografia e Estatística (IBGE) registra cerca de 60 mil casais de pessoas do mesmo sexo no Brasil (IBGE, 2015).

As pessoas LGBT (Lésbicas, gays, bissexuais, transgêneros e travestis) sempre apresentaram condutas parentais, mas nas últimas três décadas houve impulso mundial para conquista de direitos (Patterson, 2006). Existem algumas formas de conceber filhos, envolvendo a coparentalidade entre gays e lésbicas, uso de novas tecnologias, uso de terceiros na procriação (Grossi, 2003). A adoção homoparental é compreendida como a modalidade de adoção em que os candidatos a adotantes são casais formados por pessoas do mesmo sexo ou por apenas um indivíduo que se declara enquanto lésbica ou gay (Patterson, 2006). A adoção homoparental, é um meio de parentalidade mais fácil que o uso de novas tecnologias, porém, apresenta dificuldades jurídicas, que resultam em grandes filas de espera.

Questiona-se de onde surgem os empecilhos que impedem que a adoção seja consolidada por todos os órgãos nacionais, tendo em vista que o Estatuto da Criança e do Adolescente (Lei 8.069/90, Art. 42) não menciona a sexualidade dos adotandos, sugere-se que qualquer pessoa esteja apta, desde que preencha os requisitos necessários. $O$ direito ao matrimônio é uma conquista recente, em 2011 era possível a união estável, reconhecimento do Supremo Tribunal Federal e, posteriormente, o direito ao casamento igualitário, legitimado pelo Conselho Nacional de Justiça (CNJ) na Resolução $\mathrm{n}^{\circ} 175$ de 14 de maio de 2013, em 2017 em tramitações no Senado, foi acatado que todos os regimentos que abordam o matrimônio devem citar o casamento como união de duas pessoas, independentemente do sexo. Tais conquistas são fruto de militância dos grupos LGBT contra a onda de homofobia, preconceito e estigmatização presente na sociedade brasileira.

A massa populacional que exibe um discurso conservador que embasa suas representações sociais em aspectos morais e religiosos age de forma que desfavoreça a liberdade, segurança, bem-estar, igualdade e fraternidade pregados na Constituição Federal de 1988 (Pereira, Torres, Falcão, \& Pereira, 2013). Neste ponto, os adeptos a tal posicionamento político e/ou religioso julgam atitudes ditas padrões como um modelo a seguir, e quem não se enquadra nestes segmentos enfrentam diversas dificuldades nas instituições sociais, apenas um reflexo de ideologias errôneas propagadas por gerações (Verona \& Regnerus, 2014).

A posição ideológica partidária demonstra um fator que influencia nas atitudes dos sujeitos, neste sentido, sabe-se que há uma gama de interpretações sobre esquerda e direita, mas de modo geral, entende-se como pessoas com posicionamento de direita, aqueles que seguem uma visão conservadora, tradicionalista e que dá ênfase na situação econômica do país, reconhecendo os problemas sociais como algo comum em qualquer sociedade (Tarouco \& Madeira, 2013). A política da esquerda parte do princípio da igualdade social, com ações centradas nos direitos humanos numa perspectiva socialista (Madeira \& Tarouco, 2011). Os autores ressaltam ainda que existe o posicionamento central, que se situa entre estas duas posições.

Sabe-se então que a população em geral apresenta valores ancorados na orientação política. E com isso, além dos termos supracitados, há direcionamento ideológico conservador, liberal e moderado. O indivíduo que segue uma abordagem conservadora, possui crenças acerca da manutenção de costumes em torno de valores religiosos e normativos, principalmente, nas questões que envolvem sexualidade e gênero (Guerra, Gouveia, Sousa, Lima, \& Freires, 2012). O liberalismo que propaga a liberdade econômica e ideológica, explana uma postura em direção a autonomia individual e tolerância (Schwabe, Jonker, \& Berg, 2016). Aliado a tais vertentes ideológicas, e posicionado entre as duas, o pensamento moderado que exibe uma imagem menos extremista, avaliando entre liberal-conservador, sendo intermediário (Guerra et al., 2012; Tarouco \& Madeira, 2013).

Estudos demonstram que pessoas conservadoras têm menos tendência a compreender a adoção 
por casais formados por pessoas do mesmo sexo como algo em progresso na sociedade, devido ao fato de defenderem ideais baseados em pressupostos religiosos e moralísticos (Pereira et al., 2013). Com isso, as práticas de formação familiar tradicionais e visões estreitas acerca da parentalidade, predominam sobre o contexto amplo de constituição familiar (Takács, Szalma, \& Bartus, 2016). Destarte, um estudo resultou que o conservadorismo se apresenta associado ao preconceito com qualquer aspecto acerca da diversidade sexual, a adoção é apenas um deles (A. B. Costa $\&$ Nardi, 2015). Mesmo com avanços, o preconceito sexual existe, principalmente devido à segurança pública ser deficiente e à presença de preconceito flagrante embasado pela heteronormatividade (Mello, Avelar, \& Brito, 2014).

É neste panorama entre homossexualidade, preconceito e formação familiar que muitas pessoas homossexuais se veem impossibilitadas de expressar os seus atravessamentos da orientação sexual por receio do preconceito a ser vivenciado. Neste sentido, um estudo documenta que muitos gays e lésbicas vivem sentimentos negativos e não assumem a orientação sexual, para não ter que lidar com eventos discriminatórios (Poeschl, Venâncio, \& Costa, 2012).

Diante do exposto, o presente trabalho tem como objetivo geral investigar a relação dos temas adoção homoparental, conservadorismo e preconceito, e analisar como situa o posicionamento concernindo a adoção por pares do mesmo sexo de acordo com os valores políticos ideológicos e a proximidade com pessoas homossexuais.

\section{Método}

\section{Tipo do estudo}

Trata-se de um estudo exploratório, quantitativo, com dados transversais.

\section{Participantes}

A amostra foi constituída por 731 pessoas, sendo $39,5 \%$ homens $(n=289)$ e $60,5 \%$ mulheres $(n=442)$ com a idade variando de 18 a 69 anos, tendo como média de 27,6 anos ( $D P=8.93$ ). Os participantes responderam ao questionário online que foi divulgado em redes sociais e através dos sistemas de comunicação da Universidade Federal do Piauí e Universidade Federal do Sergipe. Os dados sociodemográfico são explorados no apartado dos resultados, por ser uma forma de melhor visualização dos dados encontrados neste estudo.

\section{Instrumentos}

Questionário Sociodemográfico. Composto por 13 questões que buscou caracterizar os participantes (idade, sexo, identidade de gênero, orientação sexual, estado civil, escolaridade, quantidade de filhos, renda individual, classe econômica, religião, posicionamento político, contato com pessoas homossexuais, incluindo proximidade e amizade).

Descrição de Cenário e Perguntas Subsequentes em Relação à Adoção. Adaptado de P. A. Costa e colaboradores (2013), em que as adaptações foram apenas semânticas, este estudo foi construído e validado em Portugal, e utilizado, pela primeira vez no Brasil, pelos autores do presente artigo. Na descrição de cenário havia três vinhetas descrevendo uma família candidata a adoção de uma criança, elas foram produzidas e distribuídas aleatoriamente entre os participantes. Nas perguntas, os participantes são pedidos a avaliar as qualidades desta família como futuros pais/ mães de uma criança através de quatro questões. Uma das vinhetas é constituída por um casal heterossexual, outra por um casal gay e outra por um casal de lésbicas, todos os casais são apresentados como tendo uma relação longa e estável, um forte desejo de parentalidade, tendo estabilidade financeira e profissional, bom suporte social e estabilidade emocional. As perguntas são referentes à "boa parentalidade" (se são considerados bons pais), ao risco emocional da criança (risco de desenvolver problemas emocionais), ao risco social da criança (risco de a criança ser rejeitada ou gozada na escola) e à qualificação a adoção (se são considerados bons candidatos a adoção). As perguntas estão no formato de Likert, onde variam de 1 (discordo totalmente) a 5 (concordo totalmente). Os escores foram calculados em somatória que variava de 0 a 20 pontos.

Escala de Religiosidade/Espiritualidade. Instrumento de oito perguntas sobre religiosidade/espiritualidade desenvolvido por Cerqueira-Santos, Koller e Wilcox (2008), unifatorial com alpha de 0,83 , sendo o valor obtido neste estudo, ressalta-se que o valor do alpha no estudo de validação foi de 0,87 . A amostra foi agrupada em três níveis a partir do critério do percentil .33 (baixa, média e alta religiosidade).

Instrumento sobre Posicionamento Político (P. A. Costa e cols, 2013). Sem propriedades psicométricas. Divide a amostra em esquerda, centro e direita.

Um instrumento sobre crenças acerca da homossexualidade (Cerqueira-Santos e cols, 2008). A escala 
é composta por 29 itens do tipo Likert de 5 pontos (1 Concordo totalmente à 5 - Discordo totalmente), sendo formada por três fatores (crenças positivas, negativas e diferenças intragrupais). Para presente amostra apresentou alpha de 0,78.

Escore de Conservadorismo. Dividiu a amostra em liberais, conservadores e moderados a partir do critério do percentil .33 .

Perguntas acerca do Contato com Pessoas Homossexuais. Uma sobre a intensidade do contato (que tipo de contato tem) e outra sobre quantos amigos homossexuais o participante tem (variando de nenhum até cinco ou mais amigos).

\section{Procedimento de Coleta de Dados}

A coleta de dados foi feita através de um questionário online a partir da ferramenta do Google Docs, divulgado nas redes sociais durante seis meses, disponibilizado através de um link que encaminhava o participante para uma página contendo o Termo de Consentimento Livre e Esclarecido (TCLE). Somente após a anuência é que a coleta de dados era iniciada, com a mudança para a página com a vinheta e as quatro perguntas sobre adoção, seguida por uma página com as questões sociodemográficas e assim por diante, o participante era passível de desistência em qualquer momento da coleta de dados.

\section{Procedimentos de Análise de Dados}

Os dados de cada participante foram digitados no Statistical Package for Social Science - SPSS (versão 23) e submetidos a análises descritivas e inferenciais. Realizou-se o cálculo de estatísticas descritivas (frequência, porcentagem e média) para a amostra total, com foco nas variáveis utilizadas neste estudo: aspectos sociodemográficos, atitudes em relação a adoção homoparental, índice de conservadorismo, contato com homossexuais e homofobia. Foram executadas análises bivariadas com o uso de ANOVA tendo como variável de comparação os índices de conservadorismo, posicionamento político e contato, também foi realizado teste de correlações de Pearson entre as variáveis do estudo e, por fim, uma análise de regressão linear tendo como desfecho os escores de avaliação dos casais.

\section{Procedimentos Éticos}

Os aspectos éticos que garantem a integridade dos participantes deste estudo foram assegurados, com base na Resolução $n^{\circ} 466$ de 12 de dezembro de 2012, do Conselho Nacional de Saúde (CNS), que consiste em diretrizes e normas que regulam as pesquisas com os seres humanos, na Resolução $n^{\circ}$ 510/16 do CNS/MS e na Resolução $n^{\circ}$ 016/2000 do Conselho Federal de Psicologia. Além do Termo de Consentimento Livre e Esclarecido, foi dada a garantia de sigilo das informações pessoais e o participante teve a possibilidade de desistir da participação a qualquer momento caso sentisse qualquer efeito emocional negativo causado pelo teor do estudo. O projeto foi encaminhado ao Comitê de Ética em Pesquisa envolvendo Seres Humanos da Universidade Federal do Sergipe e aprovado (CAAE: 57225916.1.0000.5214).

\section{Resultados}

A Tabela 1 apresenta dados sociodemográficos e algumas análises preliminares acerca do posicionamento político e grau de conservadorismo, que juntamente com as escalas de avaliações dos casais adotantes, são os pontos principais do presente estudo.

Quanto aos dados sociodemográfico, a média de encontros religiosos dos participantes foi de 0,84 por semana, a maioria dos participantes $(55,5 \%)$ declararam-se exclusivamente heterossexuais, solteiros $(70,5 \%)$ e com nível de escolaridade superior incompleto (50,6\%). Quanto à religião, a maioria (35,5\%) declarou-se católico, seguido de $24,7 \%$ que disseram acreditar no Deus cristão, mas não seguir nenhuma religião, $11,7 \%$ que disseram serem católicos não praticantes, $10,3 \%$ evangélicos/protestantes, $7,7 \%$ ateus, 6,2\% espíritas e $23,8 \%$ relataram seguir outras religiões. Quanto ao escore de religiosidade, que independe da religião professada (ou a não existência dela), os participantes, considerando seus escores, foram divididos em três grupos: "Pouco religioso" (30,9\%), "Medianamente religioso" (34,3\%) e "Muito religioso" (34,7\%). Quanto ao contato com indivíduos homossexuais, a maioria da amostra relatou ter muito contato $(42,4 \%)$ e ter cinco ou mais amigos homossexuais $(52,5 \%)$.

A Tabela 2 resume os escores da avaliação acerca dos casais apresentados nas vinhetas para a concordância com a adoção. Percebe-se que o maior escore de concordância é para os casais heterossexuais, seguido por casais de lésbicas e finalmente por casal de homens gays. 
Tabela 1. Dados Sociodemográficos

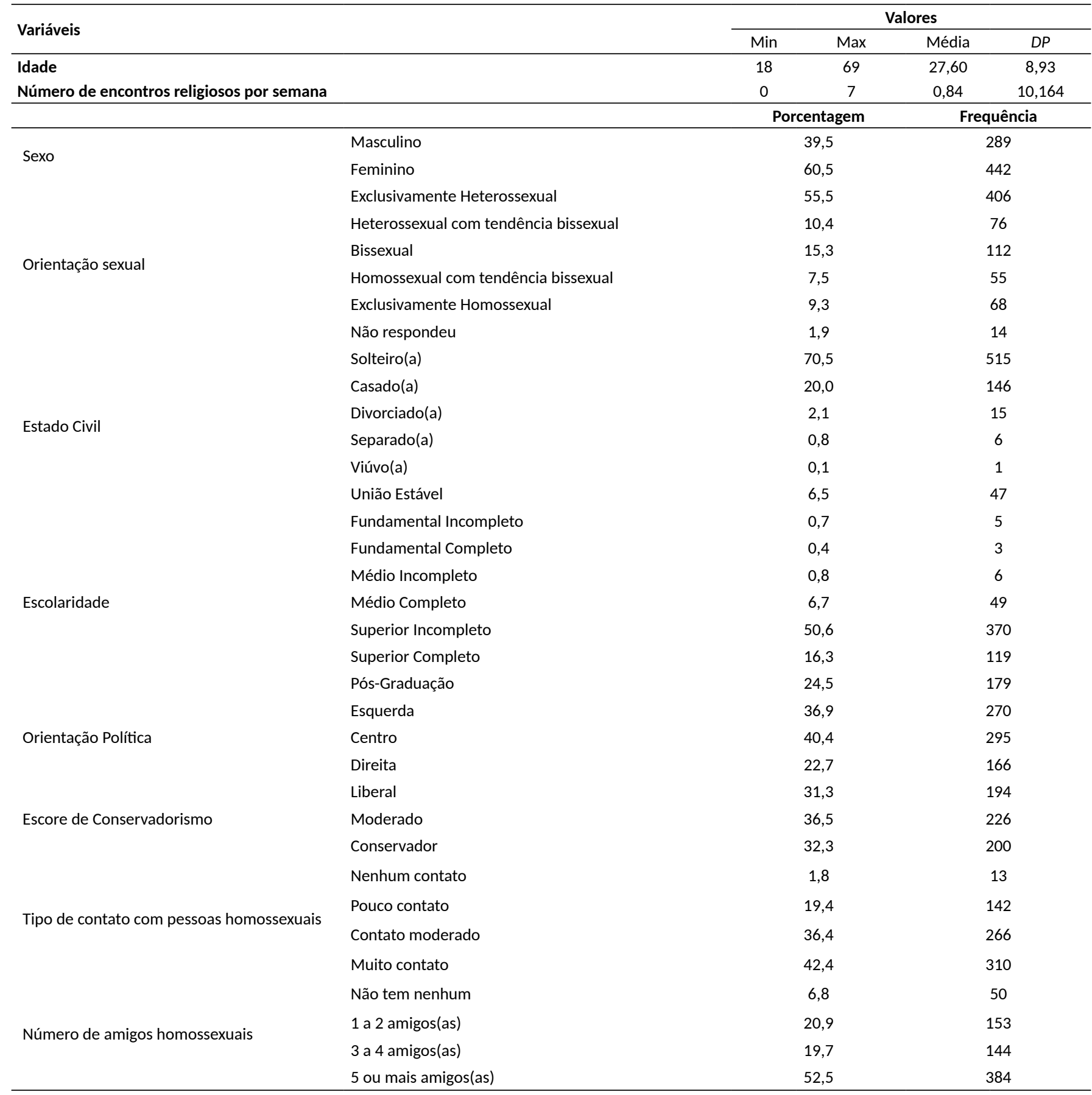

Tabela 2. Escore de Avaliação acerca dos Casais Apresentados nas Vinhetas (Escala de 0 a 20)

\begin{tabular}{ccccc}
\hline Escores & \multicolumn{4}{c}{ Valores } \\
\cline { 2 - 5 } & Min & Max & Média & $D P$ \\
\hline Casal hetero $(N=303)$ & 10 & 20 & 15,77 & 2,33 \\
Casal gay $(N=258)$ & 4 & 20 & 14,99 & 3,25 \\
Casal lésbico $(N=170)$ & 5 & 20 & 15,21 & 3,11 \\
\hline
\end{tabular}

$\mathrm{Na}$ Tabela 3, realizaram-se análises intragrupo do tipo ANOVA, para verificar as diferenças nos escores obtidos neste estudo, com as variáveis de conservadorismo, posicionamento político e contato com pessoas homossexuais. Quanto aos dados significativos, observa-se que os escores das pessoas de posicionamento político de esquerda $(M=15,63 ; M=15,89)$ são maiores 
que os escores de pessoas com o posicionamento político de direita $(M=13,55 ; M=13,86)$, levando em consideração os casais gays e lésbicos. Nos casais heterossexuais, esquerda, centro e direita apresentam valores não tão distantes, comparado as outras formações de casais, e apresenta menor valor de significância. Concernindo a variável independente do escore de conservadorismo, é notório que as pessoas liberais possuem escores maiores que as pessoas moderadas e conservadoras nos três tipos casais, as pessoas moderadas apresentam valores próximos, e o casal heterossexual $(M=15,52)$ possui maior escore, diferindo das pessoas liberais, em que os heterossexuais ( $M=16,06$ ) surgiram com menor escore. Salienta-se que de modo geral, a diferença dos escores para os casais heterossexuais não foram muito significativas. As pessoas conservadoras apresentaram escores médios para casal gay $(M=13,12)$ e casal lésbico $(12,77)$, significativamente inferior ao escore atribuído ao casal heterossexual $(M=15,44)$. Em relação a variável independente "quantidade de amigos homossexuais", encontrou-se que na avaliação do escore do casal lésbico, quanto mais amigos homossexuais, maior são os escores. No casal gay, houve uma queda de quem não possui amigos gays $(M=13,76$; $D P=3,91)$, para quem possui até dois amigos homossexuais $(M=13,28$; $D P=3,52)$, para 3 e 4 amigos $(M=14,43 ; D P=2,93)$ e 5 ou mais amigos ( $M=15,96 ; D P=2,78)$ houve elevação nos escores.

Tabela 3. ANOVA para os Escores de Avaliação dos Casais por Grau de Conservadorismo, Posicionamento Político e Contato com Homossexuais

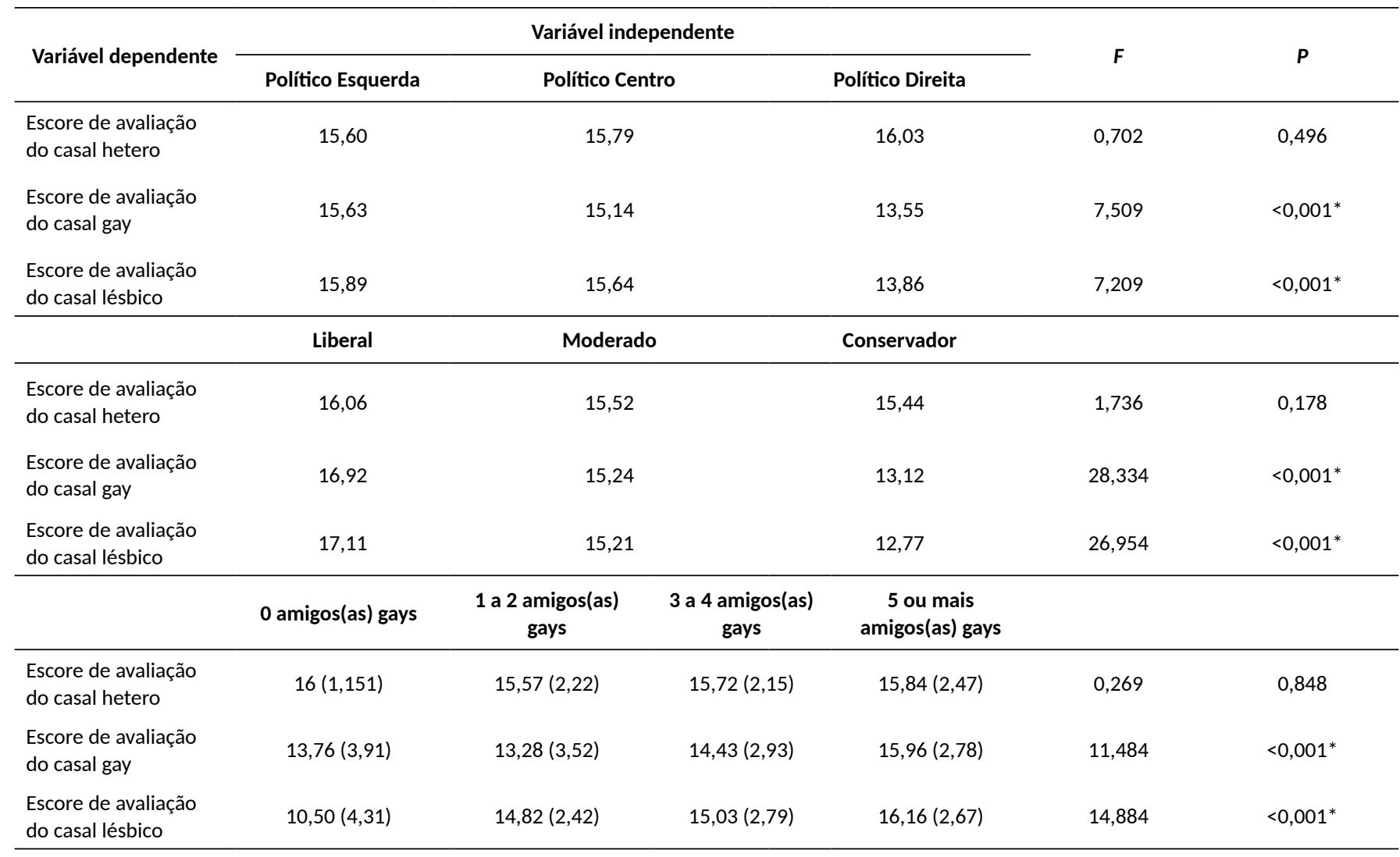

A partir da correlação de Pearson, verificou-se as variáveis com maior significância na avaliação dos três tipos de casais, em que foram utilizadas as seguintes variáveis: Escore de conservadorismo, idade, tipo de contato com pessoas homossexuais e escore de homofobia. Realizada uma regressão linear a partir da variável dependente: Avaliação dos casais gays, lésbicos e heterossexuais. Foi encontrado que o escore de conservadorismo tem alto grau preditivo no julgamento dos casais gays e lésbicos, apresentando menor significância nos casais heterossexuais. O escore de homofobia deu significativo nos modelos de casais gays e lésbicos. A avaliação sobre o casal gay tem variância explicada de $40 \%(F=39,87, p<$ $0,001)$ e sobre casal lésbico com variância explicada de $47 \%$ ( $F=35,73, p<0,001)$, para o casal heterossexual não deu significativo, com variância explicada de $5 \%(F=1,332, p=0,258)$. 
Tabela 4. Regressões Linear para Avaliação sobre a Adoção nos Três Cenários de Casais - Heterossexual, Gay e Lésbico

\begin{tabular}{|c|c|c|c|c|}
\hline Modelo & Carga & Erro Padrão & Beta & $p$ \\
\hline \multicolumn{5}{|l|}{ Escore de avaliação do casal hétero } \\
\hline Escore de conservadorismo & $-0,114$ & 0,221 & $-0,036$ & 0,607 \\
\hline Tipo de contato que tem com homossexuais & $-0,015$ & 0,155 & $-0,006$ & 0,920 \\
\hline Escore de homofobia & $-0,019$ & 0,012 & $-0,106$ & 0,124 \\
\hline Escore de conservadorismo & $-1,235$ & 0,245 & $-0,293$ & $<0,001^{*}$ \\
\hline Idade & $-0,025$ & 0,020 & $-0,065$ & 0,209 \\
\hline Tipo de contato que tem com homossexuais & 0,207 & 0,174 & 0,066 & 0,234 \\
\hline Escore de homofobia & $-0,105$ & 0,016 & $-0,394$ & $<0,001^{*}$ \\
\hline \multicolumn{5}{|l|}{ Escore de avaliação do casal Lésbico } \\
\hline Escore de homofobia & $-0,122$ & 0,019 & $-0,445$ & $<0,001^{*}$ \\
\hline
\end{tabular}

\section{Discussão}

A adoção homoparental têm se mostrado cada vez mais frequente nas pautas jurídicas, devido ao crescimento de debates de cunho psicossocial (Marmol, 2016; Dias \& Renheimer, 2013; Custódio, 2012). Porém ainda há dificuldade na consolidação de direitos devido ao fato de uma parcela populacional conservadora com estereótipos negativos e sem fundamentação científica se mostrarem contra assuntos relacionados diversidade de gênero (Pereira et al., 2013). Tais ideais são explicados devido a condenação das práticas homossexuais durante séculos, cuja ocultação da existência fez com que a sociedade evitasse discutir o assunto, afinal a influência da igreja até hoje prepondera sobre a identidade LGBT, fazendo com que muitos vivam reprimindo suas formas de devir (Mott, 2016).

Neste sentido, vê-se a homofobia como fundamento no discurso de pessoas conservadoras (A. B. Costa \& Nardi, 2015; Mott, 2016; Díaz et al., 2017), em que boa parte segue princípios políticos de direita (Díaz et al., 2017; Verona \& Regnerus, 2014; Tarouco \& Madeira, 2013). No apartado dos resultados foi possível perceber a influência do conservadorismo numa perspectiva fundamentalista que rejeita as práticas sexuais entre pessoas do mesmo sexo. Nos escores comparando a avaliação dos casais, é evidente que os participantes que se consideram de direita veem a formação de parentalidade entre gays e lésbicas de forma inferior ao modelo heterossexual.
Outro ponto é que pessoas de esquerda, centro e direita mostraram maior favorabilidade a casais lésbicos do que casais gays, que corrobora com um estudo prévio (P. A. Costa et al., 2013). Essa representação social tem sido posta em xeque, por exemplo, a partir dos estudos feministas de gênero sobre o desenvolvimento e a qualidade de vida de crianças adotadas por casais do mesmo sexo. Estudos documentam que a ausência de um dos modelos parentais não interfere no desenvolvimento infantil (Oliveira, 2016; Gato \& Fontaine, 2010).

Os resultados demonstraram a diferenciação do posicionamento entre pessoas conservadoras e liberais. A homofobia associa-se ao perfil conservador, em que as atitudes negativas confirmam suas ideologias acerca da formação familiar e adoção, o foco principal é a manutenção à noção de família tradicional (Vecho et al., 2016). O perfil liberal apresenta fundamento em estudos de psicologia e medicina, o que todavia é fruto de permissividade a compreensão de assuntos emergentes na sociedade (Ferraz, 2015; Gomes, \& Serôdio, 2014). Outro dado importante, revelado neste estudo, é que quanto mais próximo com pessoas homossexuais, maior a tendência a assimilar positivamente conteúdos sobre casais do mesmo sexo. Alguns estudos reforçam este elemento (Gato, Fontaine, \& Carneiro, 2012; Machin, 2016).

Os dados apresentados demonstram o que outras pesquisas encontraram ao correlacionar conservadorismo e homossexualidade, e acrescenta que o conhecimento acerca da vida de pessoas LGBT, livre de estereótipos errôneos, ocasiona em posicionamentos favoráveis. 
Denota-se a negligência com assuntos sobre homossexualidade, principalmente quando envolve a adoção de crianças, tendo em vista que muitos julgam como uma atitude inadequada ao desenvolvimento infantil, como documenta alguns estudos (Freires, 2015; Pereira et al., 2013). O fato é que este tipo de julgamento é embasado em princípios morais tradicionais irrefletidos e religiosos, desconsiderando qualquer outro aspecto que venha a favorecer a equidade de direitos. Outro estudo, que aborda sobre as representações sociais da do desenvolvimento infantil em famílias homoparentais, infere que a maioria dos participantes não se considera preconceituoso, porém cita que uma criança criada por casais do mesmo sexo irá sofrer preconceito pela sociedade (Santos, Araújo, Negreiros, \& Cerqueira-Santos, 2018).

Este estudo nos apresenta a necessidade das políticas públicas voltadas as famílias homoparentais, afinal diante de tal repercussão social, as conquistas jurídicas concretizam a implementação de direitos que contribuem para a segurança e qualidade de vida destas famílias. Sabe-se das dificuldades que as pessoas LGBT enfrentam com uma Frente Parlamentar Evangélica que não conseguem separar seus dogmas religiosos de sua atuação política (Prandi \& Santos, 2017). Quanto à adoção homoparental, alguns casais conseguiram através do processo normal de adoção, devido a não menção do gênero e orientação sexual dos casais adotantes no Estatuto da Criança e do Adolescente, mas mesmo assim ainda vivenciam empecilhos judiciais que poderiam ser mais fáceis se houvesse alguma lei concreta de amparo a estas conjunturas familiares (Santos et al., 2018).

\section{Considerações finais}

Os dados do estudo explanaram que o contato com pessoas homossexuais age como um subsídio de atitudes que exploram o sentido de compreensão e respeito. Demonstrou-se que pessoas conservadoras tem menos tendência a aceitar a adoção por homossexuais do que pessoas liberais. Além disto, a parte populacional que se considera de esquerda, apresenta maior propensão a interpretar positivamente a adoção homoparental.

Pode-se ainda destacar que a maioria das variáveis apresentadas demonstram a maior aceitação dos casais lésbicos, do que casais gays, exceto, na variável de conservadorismo, cujo a diferenciação é mínima, o que fundamenta o contexto de que ambas se situam abaixo da adoção por casais heterossexuais, independentemente de ser casal gay ou lésbico. As pessoas de esquerda foram às únicas a apresentarem maior favorabilidade a casais homoparentais. É notório então que a hegemonia do preconceito se reduz diante da interação entre pessoas homossexuais e heterossexuais, pois a partir disto, observam-se as diferenças e as igualdades, no qual se busca orientações em equidade para atender as necessidades de cada grupo.

A presente pesquisa alcançou seus objetivos, apontando que as variáveis demonstraram o que a literatura já tem produzido em outros contextos que envolvem homossexualidade e conservadorismo. Como limitação, têm-se a coleta dos participantes, em que houve muita recusa, o que, todavia era devido ao fato do assunto ser considerado um tabu entre muitos participantes. Além disto, não existem muitos estudos a partir da perspectiva entre conservadorismo, posicionamento político e adoção homoparental.

Os dados deste estudo evidenciam a necessidade de políticas educacionais que atinjam a toda população, e não apenas pessoas que se mostrem assertivas ao tema, afinal de nada adianta a militância enquanto ela girar em torno apenas dos próprios militantes. Há décadas a sociedade se apresenta em avanço e a psicologia social tem papel fundamental na construção de paradigmas que permeiam a visibilidade da população LGBT. Espera-se que os encontrados venham a subsidiar estudos com o escopo de favorecer a elaboração de regimentos que tragam direitos as pessoas LGBT.

\section{Referências}

Cerqueira-Santos, E., Koller, S. H., \& Wilcox, B. (2008). Condom use, contraceptive methods, and religiosity among youths of low socioeconomic level. The Spanish Journal of Psychology, 11(1), 94-102.

Cerqueira-Santos, E. \& Santana, G. (2015). Adoção homoparental e preconceito: crenças de estudantes de direito e serviço social. Temas em Psicologia, 23(4), 873- 885. doi: 10.9788/TP2015.4-06

Costa, A. B., \& Nardi, H. C. (2015). Homofobia e preconceito contra diversidade sexual: debate conceitual. Temas em psicologia, 23(3), 715-726. doi: 10.9788/TP2015.3-15

Costa, P. A., Caldeira, S., Fernandes, I., Rita, C., Pereira, H., \& Leal, I. (2013). Atitudes da população portuguesa em relação à homoparentalidade. Psicologia: Reflexão e Crítica, 26(4), 790-798. doi: 10.1590/S0102-79722013000400020

Custódio, J. (2012). Homoparentalidade: um direito em construção. Espaço Jurídico: Journal of Law, 13(1), 91-100. Recuperado de http://editora.unoesc.edu.br/index.php/espacojuridico/article/ view/1426

Dias, M. B., \& Reinheimer, T. L. (2013). Homoparentalidade: uma realidade. In C. J. Cordeiro \& J. A. Gomes. (Org.), Temas contemporâneos de direito das famílias. (ed.1, pp. 6-503). São Paulo: Pillares. 
Díaz, F. H., Bobowik, M., Abarca, X. F., \& Moya, J. S. (2017). Xenofobia y homofobia como efectos de la orientación política, religión y sexo mediados por clasismo y patriocentrismo en jóvenes universitarios chilenos. Revista Colombiana de Psicología, 26(1), 131-148. doi: 10.15446/rcp.v26n1.55687

Ferraz, M. C. (2015). Religião e homossexualidade nos Estados Unidos: vertentes liberais e conservadoras em debate. In Associação Brasileira de História das Religiões (Org.), Anais do XIV Simpósio Nacional da ABHR (Vol. 14, pp. 476-492). Juiz de Fora, MG. Recuperado de http:// www.abhr.org.br/plura/ojs/index.php/anais/article/view/973

Freires, L. A. (2015). Atitudes frente à homoparentalidade: uma explicação a partir de variáveis explícitas e implícitas (Tese de doutorado). Recuperado de http://tede.biblioteca.ufpb.br:8080/handle/tede/752

Gato, J., \& Fontaine, A. M. (2010). Desconstruindo preconceitos sobre a homoparentalidade. LES Online, 2(2), 14-21. Recuperado de https://lesonlinesite.files.wordpress.com/2017/03/desconstruindo-preconceitos-sobre-a-homoparentalidade.pdf

Gato, J., Fontaine, A. M., \& Carneiro, N. S. (2012). Escala multidimensional de atitudes face a lésbicas e a gays: construção e validação preliminar. Paidéia (Ribeirão Preto), 22(51), 11-20. doi: 10.1590/ S0103-863X2012000100003

Gomes, I. S., \& Serôdio, R. G. (2014). A homofobia perspetivada à luz da abordagem da identidade social: Níveis de autodefinição identitária e atitude em relação a pessoas homossexuais. Análise Psicológica, 32(2), 215-230. doi: 10.14417/ap.803

Grossi, M. P. (2003). Gênero e parentesco: famílias gays e lésbicas no Brasil. Cadernos Pagu, 21, 261-280. doi: 10.1590/ S0104-83332003000200011

Guerra, V. M., Gouveia, V. V., Sousa, D. M., Lima, T. J., \& Freires, L. A. (2012). Sexual liberalism-conservatism: the effect of human values, gender, and previous sexual experience. Archives of Sexual Behavior, 41(4), 1027-1039. doi: 10.1007/s10508-012-9936-4

Instituto Brasileiro de Geografia Estatística. (2015). Pesquisa Nacional por Amostra de Domicílios: síntese de indicadores 2014. Coordenação de Trabalho e Rendimento. Rio de Janeiro: Autor. Recuperado de http://biblioteca.ibge.gov.br/visualizacao/livros/liv94935.pdf

Lei no 8.069, de 13 de Julho de 1990. (1990, 13 de julho). Dispõe sobre - Estatuto da Criança e do Adolescente e dá outras providências. Diário Oficial da União, seção 1.

Machin, R. (2016). Homoparentalidade e adoção: (re) Afirmando seu lugar como família. Psicologia \& Sociedade, 28(2), 350-359. doi: 10.1590/1807-03102016v28n2p350

Madeira, R. M., \& Tarouco, G. S. (2011). Esquerda e direita no Brasil: uma análise conceitual. Revista Pós Ciências Sociais, 8(15), 171-186. Recuperado de http://www.periodicoseletronicos.ufma. br/index.php/rpcsoc/article/view/591/2744

Marmol, I. C. N. (2016). Perspectivas da adoção em famílias homoparentais. Intertem@ s ISSN 1677-1281, 29(29). Recuperado de http:// intertemas.toledoprudente.edu.br/revista/index.php/Juridica/article/ view/5262/5014

Mello, L., Avelar, R. B., \& Brito, W. (2014). Políticas públicas de segurança para a população LGBT no Brasil. Estudos Feministas, 22(1), 297-320. Recuperado de https://periodicos.ufsc.br/index.php/ref/ article/view/S0104-026X2014000100016/26814

Mott, L. (2016). Homofobia: uma praga cristã. e-hum, 9(2), 66-73.
Oliveira, R. A. G. (2016). Homoparentalidade e desenvolvimento infantil (Dissertação de Mestrado). Recuperado de http://hdl.handle. net/10216/84364

Patterson, C. J. (2006). Children of lesbian and gay parents. Current Directions in Psychological Science, 15(5), 241-244. doi: 10.1111/j.1467-8721.2006.00444.x

Pereira, C. R., Torres, A. R. R., Falcão, L., \& Pereira, A. S. (2013). O papel de representações sociais sobre a natureza da homossexualidade na oposição ao casamento civil e à adoção por famílias homoafetivas. Psicologia: Teoria e Pesquisa, 29(1), 79-89. doi: 10.1590/S0102-37722013000100010

Poeschl, G., Venâncio, J., \& Costa, D. (2012). Consequências da (não) revelação da homossexualidade e preconceito sexual: o ponto de vista das pessoas homossexuais. Psicologia, 26(1), 33-53. Recuperado de http://www.scielo.mec.pt/scielo.php?scrip-

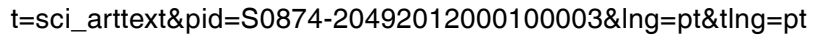

Prandi, R., \& Santos, R. (2017). Quem tem medo da bancada evangélica? Posições sobre moralidade e política no eleitorado brasileiro, no Congresso Nacional e na Frente Parlamentar Evangélica. Tempo Social, 29(2), 187-213. doi: 10.11606/0103-2070.ts.2017.110052

Resolução nº 016/2000. (2000, 20 de dezembro). Dispõe sobre a realização de pesquisa em Psicologia com seres humanos. Brasília, DF: Conselho Federal de Psicologia.

Resolução no 175. (2013, 14 de maio). Dispõe sobre a habilitação, celebração de casamento civil, ou de conversão de união estável em casamento, entre pessoas de mesmo sexo. Brasília, DF: Conselho Nacional de Justiça.

Resolução $n^{\circ}$ 466. (2012, 12 de dezembro). Aprova as diretrizes e normas regulamentadoras de pesquisas envolvendo seres humanos. Brasília, DF: Conselho Nacional de Saúde.

Resolução no 510. (2016, 07 de abril). dispõe sobre as normas aplicáveis a pesquisas em Ciências Humanas e Sociais. Brasília, DF: Conselho Nacional de Saúde.

Santos, J. V. O., Araújo, L. F., Negreiros, F., \& Cerqueira-Santos, E. (2018). Adoção de Crianças por casais homossexuais: as representações sociais. Temas em Psicologia, 26(1), 139-152. doi: 10.9788/ tp2018.1-06pt

Schwabe, I., Jonker, W., \& Berg, S. M. (2016). Genes, culture and conservatism-A psychometric-ggenetic approach. Behavior Genetics, 46(4), 516-528. doi: 10.1007/s10519-015-9768-9

Takács, J., Szalma, I., \& Bartus, T. (2016). Social attitudes toward adoption by same-sex couples in europe. Archives of Sexual Behavior, 45(7), 1787-1798. doi: 10.1007/s10508-016-0691-9

Tarouco, G. S., \& Madeira, R. M. (2013). Partidos, programas e o debate sobre esquerda e direita no Brasil. Revista de Sociologia e Política, 21(45), 149-165. doi: 10.1590/S0104-44782013000100011

Vecho, O., Gross, M., Gratton, E., D’Amore, S., \& Green, R. J. (2016). Attitudes des étudiants hétérosexuels envers le mariage des personnes de même sexe et l'homoparentalité en France. Les Cahiers Internationaux de Psychologie Sociale, (3), 305-339. doi :10.3917/ cips. 111.0305

Verona, A. P. A., \& Regnerus, M. (2014). Pentecostalismo e iniciação sexual pré-marital no Brasil. Revista Brasileira de Estudos de População, 31(1), 99-115. Recuperado de https://www.rebep.org. br/revista/article/view/644/pdf_611 
José Victor de Oliveira Santos, Graduação em Psicologia pela Universidade Federal do Piauí. Endereço para correspondência: Universidade Federal do Piauí (UFPI), Campus de Parnaíba,

Departamento de Psicologia. Av. São Sebastião, 2819, Cidade Universitária - Parnaíba, PI - Brasil. CEP 64.202-020 Telefone para contato: (86) 999909208 - Fax: (86) 33235248.

E-mail: victorolintos@hotmail.com

Ludgleydson Fernandes de Araújo, Doutor em Psicologia pela Universidade de Granada (UGR), Espanha, é Professor no quadro Permanente do Programa de Pós-Graduação em Psicologia (Stricto Sensu) do Campus Ministro Reis Velloso da Universidade Federal do Piauí (UFPI). E-mail: ludgleydson@yahoo.com.br

Elder Cerqueira-Santos, Doutor em Psicologia pela Universidade Federal do Rio Grande do Sul (UFRGS), é Professor no quadro Permanente do Programa de Pós-Graduação em Psicologia (Stricto Sensu) da Universidade Federal de Sergipe (UFS). E-mail: eldercerqueira@gmail.com

Fauston Negreiros, Doutor em Educação pela Universidade Federal do Ceará (UFC), é Professor no quadro Permanente do Programa de Pós-Graduação em Psicologia (Stricto Sensu) do Campus Ministro Reis Velloso da Universidade Federal do Piauí (UFPI). E-mail: faustonnegreiros@ufpi.edu.br 